\title{
PEITC inhibits human brain glioblastoma GBM 8401 cell migration and invasion through the inhibition of uPA, Rho A, and Ras with inhibition of MMP-2, -7 and -9 gene expression
}

\author{
YU-CHENG CHOU ${ }^{1-4}$, MENG-YA CHANG ${ }^{2 *}$, MEI-JEN WANG ${ }^{2,10}$, FU-SHUN YU $^{5}$, HSIN-CHUNG LIU ${ }^{6}$, \\ TOMOR HARNOD ${ }^{7}$, CHIH-HUANG HUNG ${ }^{2}$, HSU-TUNG LEE ${ }^{1,8}$ and JING-GUNG CHUNG ${ }^{6,9^{*}}$

\begin{abstract}
${ }^{1}$ Division of Neurosurgical Oncology, Neurological Institute, Taichung Veterans General Hospital, Taichung 407;
${ }^{2}$ Institute of Medical Sciences, Tzu Chi University, Hualien 970; ${ }^{3}$ School of Medicine, National Defense Medical Center, Taipei 114; ${ }^{4}$ Rong Hsing Research Center for Translational Medicine, National Chung Hsing University, Taichung 402; ${ }^{5}$ School of Dentistry, China Medical University, Taichung 404; ${ }^{6}$ Department of Biological Science

Hospital and College of Medicine, Tzu Chi University, Hualien 970; ${ }^{8}$ Graduate Institute of Medical Sciences, National Defense Medical Center, Taipei 114; ${ }^{9}$ Department of Biotechnology, Asia University, Taichung 413;

${ }^{10}$ Department of Medical Research, Buddhist Tzu Chi General Hospital, Hualien 970, Taiwan, R.O.C.
\end{abstract} \\ and Technology, China Medical University, Taichung 404; ${ }^{7}$ Department of Neurosurgery, Buddhist Tzu Chi General
}

Received June 25, 2015; Accepted July 24, 2015

DOI: $10.3892 /$ or.2015.4260

\begin{abstract}
Glioblastoma is the most aggressive primary brain malignancy, and the efficacy of multimodality treatments remains unsatisfactory. Phenethyl isothiocyanate (PEITC), one member of the isothiocyanate family, was found to inhibit the migration and invasion of many types of human cancer cells. In our previous study, PEITC induced the apoptosis of human brain glioblastoma GBM 8401 cells through the extrinsic and intrinsic signaling pathways. In the present study, we first investigated the effects of PEITC on the migration and invasion of GBM 8401 cells. PEITC decreased the migration of GBM 8401 cells in a dose-dependent manner as determined from scratch wound healing and Transwell migration assays. The percentage of inhibition ranged from 46.89 to $15.75 \%$, and from 27.80 to $7.31 \%$ after a 48 -h treatment of PEITC as determined from the Transwell migration assay and invasion assay, respectively. The western blot analysis indicated that PEITC decreased the levels of proteins associated with migration and invasion, Ras, uPA, RhoA, GRB2, p-p38, p-JNK, p-ERK, p65, SOS1, MMP-2, MMP-9 and MMP-13, in a dose-dependent manner. Real-time PCR analyses revealed
\end{abstract}

Correspondence to: Professor Jing-Gung Chung, Department of Biological Science and Technology, China Medical University, No 91, Hsueh-Shih Road, Taichung 404, Taiwan, R.O.C.

E-mail: jgchung@mail.cmu.edu.tw

*Contributed equally

Key words: PEITC, migration, invasion, matrix metalloproteinases, glioblastoma that PEITC reduced the mRNA levels of MMP-2, MMP-7, MMP-9 and RhoA in a dose- and time-dependent manner. PEITC exhibited potent anticancer activities through the inhibition of migration and invasion in the GBM 8401 cells. Our findings elucidate the possible molecular mechanisms and signaling pathways of the anti-metastatic effects of PEITC on human brain glioblastoma cells, and PEITC may be considered as a therapeutic agent.

\section{Introduction}

Glioblastoma is the most aggressive primary brain malignancy with a median survival rate of 14.6 months from diagnosis in unselected patients, even following maximal, feasible surgical resection, radiotherapy and standard adjuvant temozolomide (TMZ) therapy (1). Only $0.4-0.5 \%$ of all GBM patients with extracranial metastasis has been reported, which may be attributable to the extremely shortened survival of these patients (2). Combining radiotherapy and TMZ provides better survival outcomes of glioblastoma patients than radiotherapy alone (3). Survival and recurrence are significantly associated with the extent of resection and residual volume (4). Gross total resection associated with survival improvement is not always possible as the preservation of neurological functions is necessary. The efficacy of current multimodality treatments including surgery, radiotherapy, chemotherapy for this tumor remains unsatisfactory.

Phenethyl isothiocyanate (PEITC) is one of the most extensively studied isothiocyanates (5). PEITC can induce cell cycle arrest and apoptotic cell death in various tumor types (6-12). In our previous study, PEITC induced apoptosis through the extrinsic (death receptor) and intrinsic (mitochondrial) pathways, dysfunction of mitochondria and ROS-induced ER stress in GBM 8401 cells (13). PEITC displayed anti-metastatic 
effects in vivo in a novel breast tumor metastasis model (14), and inhibited tumor migration and invasion via suppression of multiple signal transduction pathways in human colon cancer HT29 cells (15). Yet, there is no available literature concerning how PEITC affects the migration and invasion of human brain glioblastoma cells.

In the present study, we investigated the effects of PEITC on human brain glioblastoma cells in regards to migration and invasion through the signaling transduction pathways in GBM 8401 cells.

\section{Materials and methods}

Chemicals and reagents. PEITC, dimethyl sulfoxide (DMSO), propidium iodide (PI), RNase, Tris- $\mathrm{HCl}$, Triton X-100 and trypan blue were obtained from Sigma Chemical Co. (St. Louis, MO, USA). RPMI-1640, fetal bovine serum (FBS), L-glutamine, penicillin-streptomycin and trypsin-EDTA were purchased from Gibco-BRL/Invitrogen (Carlsbad, CA, USA). Matrigel invasion chambers were obtained from BD Biosciences (San Jose, CA, USA).

Cell culture. The GBM 8401 cell line was purchased from the Food Industry Research and Development Institute (Hsinchu, Taiwan). Cells were plated onto $75-\mathrm{cm}^{2}$ tissue culture flasks in RPMI-1640 medium supplemented with 10\% FBS, $100 \mathrm{U} / \mathrm{ml}$ penicillin and $100 \mu \mathrm{g} / \mathrm{ml}$ streptomycin, $2 \mathrm{mM} \mathrm{L}$-glutamine and grown at $37^{\circ} \mathrm{C}$ under a humidified $5 \% \mathrm{CO}_{2}$ and $95 \%$ air at one atmosphere. The cells were subcultured with a solution of $0.25 \%$ trypsin and $0.02 \%$ EDTA. The medium was changed every 2 days (16).

Cell morphological changes and viability. GBM 8401 cells $\left(1.6 \times 10^{5}\right.$ cells/well) on a 12 -well plate were treated with $0,0.5$, 1,2 and $4 \mu \mathrm{M}$ PEITC, or 0 and $500 \mu \mathrm{M}$ TMZ, and incubated for 0,24 and $48 \mathrm{~h}$. Cells in each well were examined, and representative images were captured at $\times 200$ magnification using a Nikon TE2000-U inverted microscope for morphological change examinations. After cells from each well were trypsinized and collected by centrifugation at $1500 \mathrm{rpm}$ for $5 \mathrm{~min}$, and washed twice with PBS, $5 \mu \mathrm{g} / \mathrm{ml}$ PI in PBS was added to determine the percentage of viable cells. Non-viable cells were stained by PI dye exclusion (indicative of an intact membrane) and displayed brighter fluorescence than the unstained (viable) cells. Cells were counted by flow cytometric analysis with FACS Calibur utilizing CellQuest software (Becton-Dickinson, San Jose, CA, USA) (17).

Scratch wound healing assay. GBM 8401 cells $\left(1 \times 10^{5}\right.$ cells/well) were placed for $24 \mathrm{~h}$ in 6 -well plates, and a wound at confluence was made with a pipette tip followed by washing with serum-free medium to remove cell debris. The cells were photographed under phase contrast microscopy (time $=0$ ) and then incubated in media with PEITC $(0,2$ and $4 \mu \mathrm{M})$, or with $\mathrm{TMZ}(500 \mu \mathrm{M})$ at $37^{\circ} \mathrm{C}$ in $5 \% \mathrm{CO}_{2}$ and allowed to migrate into the wound area for up to $48 \mathrm{~h}$. Cells were gently washed with phosphate-buffered saline (PBS). Images of the scratch wounds were quantified by ImageJ software. The migration inhibition rate $=$ (original scratch width - new scratch width $)$ / original scratch width x $100 \%$ (18).
Migration assay. GBM 8401 cells were cultured in serumfree RPMI-1640 medium containing 1\% charcoal-stripped FBS for $48 \mathrm{~h}$. The lower chamber of the Transwell filter was coated with $10 \mu \mathrm{g}$ type IV collagen, and the lower chamber of each well was filled with RPMI-1640 supplemented with $1 \%$ charcoal-stripped FBS. The filter in the 6.5-mm Transwell was inserted in the 24-well plates, and the GBM 8401 cells $\left(\sim 3.2 \times 10^{4}\right.$ cells/filter) were placed on the filter. The cells were treated with 0,2 and $4 \mu \mathrm{M}$ PEITC and $500 \mu \mathrm{M}$ TMZ for $48 \mathrm{~h}$. Migrated cells were stained with $2 \%$ crystal violet and were then examined and photographed under a microscope $(16,19)$.

Invasion assay. The same protocol was carried out as described in the migration assay except that cells were placed on a Matrigel-coated Transwell filter (Matrigel invasion chamber; BD Biosciences) and were then examined and photographed under a microscope $(16,19)$.

Gelatin zymography assay. GBM 8401 cells (1.6x10 $10^{5}$ cells/well) were plated on 12-well tissue culture plates and incubated with 0,2 and $4 \mu \mathrm{M}$ PEITC or $500 \mu \mathrm{M}$ TMZ for 24 and $48 \mathrm{~h}$. The conditioned medium was collected and separated by electrophoresis on $10 \%$ SDS-PAGE with $0.2 \%$ gelatin (Sigma-Aldrich Corp.). The gels were soaked in $2.5 \%$ Triton $\mathrm{X}-100$ in $\mathrm{dH}_{2} \mathrm{O}$ twice for a total of $60 \mathrm{~min}$ at $25^{\circ} \mathrm{C}$ at the end of the electrophoresis, and they were incubated in substrate buffer $(50 \mathrm{mM}$ Tris $\mathrm{HCl}, 5 \mathrm{mM} \mathrm{CaCl}_{2}, 0.02 \% \mathrm{NaN}_{3}$ and $1 \%$ Triton $\mathrm{X}-100$, $\mathrm{pH} 8.0$ ) at $37^{\circ} \mathrm{C}$ for $18 \mathrm{~h}$. Bands related to the enzyme activity of MMP-2 were visualized by negative staining using $0.2 \%$ Coomassie blue in $50 \%$ methanol and $10 \%$ acetic acid (20). The bands were evaluated by Image $\mathbf{J}$ software.

Western blot assay. GBM 8401 cells $\left(2.4 \times 10^{6}\right.$ cells/dish) were placed in a $10-\mathrm{cm}$ dish, and 0,2 and $4 \mu \mathrm{M}$ PEITC or $500 \mu \mathrm{M}$ $\mathrm{TMZ}$ were added to the cells. The cells were incubated for $48 \mathrm{~h}$. The cells were collected and lysed in lysate buffer composed of $50 \mu \mathrm{M}$ Tris ( $\mathrm{pH} 8.0$ ), $150 \mu \mathrm{M} \mathrm{NaCl}, 5 \mu \mathrm{M}$ ethylenediaminetetraacetic acid and $0.5 \%$ NP-40 with protease inhibitor solution (Roche, Mannheim, Germany). The protein concentration from each treatment was determined using the Bio-Rad protein assay kit. Approximately $30 \mu \mathrm{g}$ of protein from each sample was separated on a $10 \%$ sodium dodecyl sulfate-polyacrylamide electrophoretic gel (SDS-PAGE) and transferred to nitrocellulose membranes (GE Healthcare, Piscataway NJ, USA). The blot was soaked with blocking buffer, $5 \%$ non-fat dry milk in Tris-buffered saline containing Tween-20 (TBS-T) for $1 \mathrm{~h}$ at $25^{\circ} \mathrm{C}$. They were incubated with the specific primary antibodies for matrix metalloproteinase (MMP)-2, MMP-9, Ras, urokinase-type plasminogen activator (uPA), Ras homolog gene family, member A (RhoA), growth factor receptor-bound protein 2 (GRB2), p-p38, phospho-Jun $\mathrm{NH} 2$-terminal kinase (p-JNK), p-extracellular-signal-regulated kinases (p-ERK), p65, Son of sevenless homolog 1 (SOS1), rho-associated coiled-coil-containing protein kinase 1 (Rock1) and MMP-13 (Santa Cruz Biotechnology, Santa Cruz, CA, USA) in blocking buffer at $4^{\circ} \mathrm{C}$ overnight. Immunoreactive proteins were detected with horseradish peroxidase-conjugated secondary antibodies and detected by chemiluminescence (GE Healthcare) and autoradiography using BioMax LightFilm (Eastman Kodak, New Heaven, CT, 
Table I. Primer sequence used for real-time PCR.

\begin{tabular}{ll}
\hline Primer name & \multicolumn{1}{c}{ Primer sequence } \\
\hline MMP-2 & F: CCCCAGACAGGTGATCTTGAC \\
& R: GCTTGCGAGGGAAGAAGTTG \\
MMP-7 & F: GGATGGTAGCAGTCTAGGGATTAACT \\
& R: AGGTTGGATACATCACTGCATTAGG \\
MMP-9 & F: CGCTGGGCTTAGATCATTCC \\
& R: AGGTTGGATACATCACTGCATTAGG \\
RhoA & F: TCAAGCCGGAGGTCAACAAC \\
& R: ACGAGCTGCCCATAGCAGAA \\
GAPDH & F: ACACCCACTCCTCCACCTTT \\
& R: TAGCCAAATTCGTTGTCATAC \\
\hline
\end{tabular}

MMP, matrix metalloproteinase; RhoA, RAS homologue gene family member A; GAPDH, glyceraldehyde-3-phosphate dehydrogenase; F, forward primer; $\mathrm{R}$, reverse primer.

USA) (21). The relative protein amounts from each treatment were assessed by densitometry scanning of the X-ray film, and analyzed by Eagle Eye Image system (Stratagene, La Jolla, CA, USA).

Real-time polymerase chain reaction (RT-PCR). GBM 8401 cells $\left(2.4 \times 10^{6}\right.$ cells/dish) on $10-\mathrm{cm}$ dish were treated with 0,2 and $4 \mu \mathrm{M}$ PEITC, or $500 \mu \mathrm{M} \mathrm{TMZ}$, and incubated for 24 and $48 \mathrm{~h}$. The cells from each sample were collected, and the total RNA was extracted using the Qiagen RNeasy Mini kit as previously described $(16,22)$. According to the standard protocol of the supplier (Applied Biosystems), all RNA samples were reverse-transcribed for $30 \mathrm{~min}$ at $42^{\circ} \mathrm{C}$ with High Capacity cDNA reverse transcription kit. Quantitative PCR conditions were: $2 \mathrm{~min}$ at $50^{\circ} \mathrm{C}, 10 \mathrm{~min}$ at $95^{\circ} \mathrm{C}$, and 40 cycles of 15 sec at $95^{\circ} \mathrm{C}, 1 \mathrm{~min}$ at $60^{\circ} \mathrm{C}$ using $1 \mu \mathrm{l}$ of the cDNA reversetranscribed as described above, $2 \mathrm{X}$ SYBR-Green PCR Master Mix (Applied Biosystems) and $200 \mathrm{nM}$ of the forward and reverse primers as shown in Table I. Each assay was processed using the Applied Biosystems 7300 Real-Time PCR system in triplicate, and fold-changes in expression were measured using the comparative $\mathrm{CT}$ method. The ratios of gene expression to that of GAPDH are presented.

Statistical analysis. Results are expressed as mean \pm SD of 3 experiments. Differences between the PEITC-treated (experimental group) or the TMZ-treated (positive control group), and the vehicle control group were evaluated using the Student's t-test. A P-value $<0.05$ was considered to indicate a statistically significant difference. P-values are indicated in the figure legends

\section{Results}

Effect of PEITC on cell morphological changes and the viability of GBM 8401 cells. GBM 8401 cells were treated with $0,0.5,1,2$ and $4 \mu \mathrm{M}$ PEITC or $500 \mu \mathrm{M} \mathrm{TMZ}$ for 24
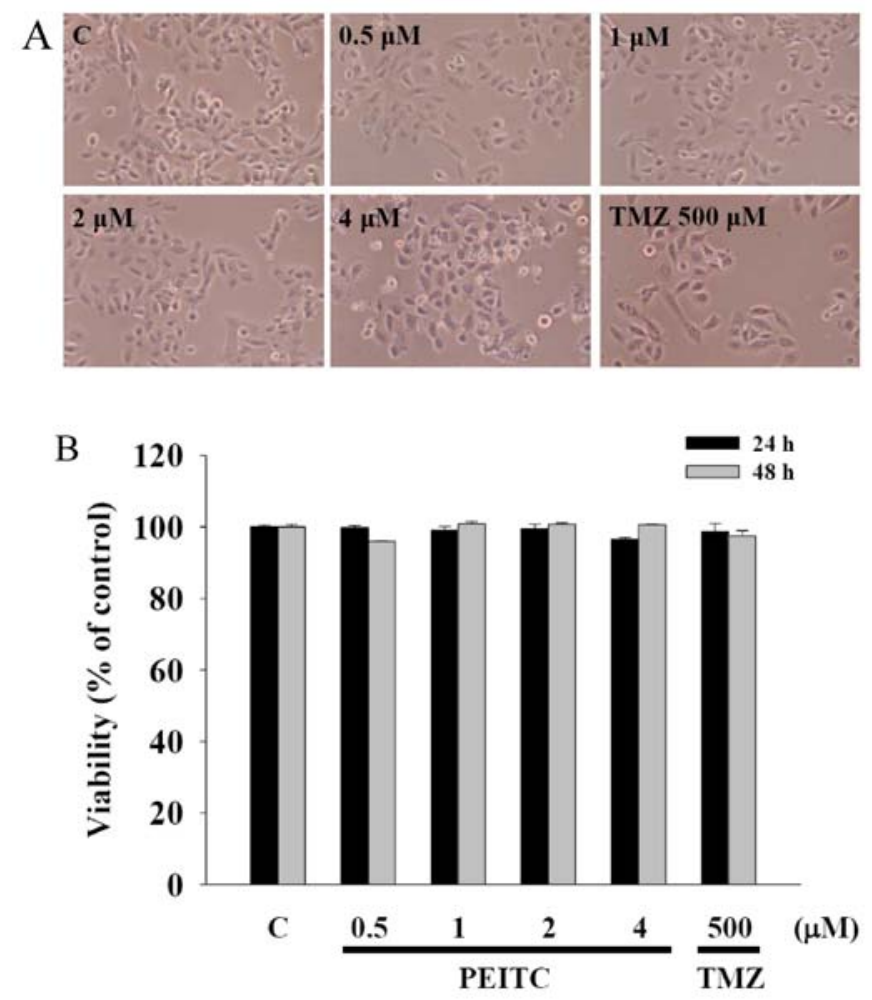

Figure 1. PEITC and TMZ did not induce marked cell morphological changes and did not decrease the percentage of viable GBM 8401 cells. (A) Cells were treated with different concentrations $(0.5-4 \mu \mathrm{M})$ of PEITC for 24 and $48 \mathrm{~h}$ and cell morphological changes were examined under phase contrast microscope at $\times 200$ magnification. (B) Cells were harvested to calculate the percentage of viable cells by flow cytometric assay. The values presented are the mean $\pm S D(n=3)$ from three independent experiments. There was no significant difference between PEITC-treated (experimental group) or TMZtreated (positive control group) and the vehicle control group. C, control; TMZ, temozolomide.

and $48 \mathrm{~h}$ to determine the cytotoxic effects of PEITC. No marked morphological change in the GBM 8401 cells was induced by PEITC (Fig. 1A). Total percentages of viable cells were measured by flow cytometric assay. PEITC or TMZ did not decrease the percentage of viable GBM 8401 cells in a dose- and time-dependent manner (Fig. 1B). The total number of viable cells was not significantly decreased in the GBM 8401 cells following exposure to concentrations as high as $4 \mu \mathrm{M}$ PEITC or $500 \mu \mathrm{M}$ TMZ after a $24-$ and 48 -h treatment. Consequently, concentrations of $\leq 4 \mu \mathrm{M}$ PEITC or $500 \mu \mathrm{M}$ $\mathrm{TMZ}$ were selected for use in subsequent experiments.

PEITC inhibits the migration of GBM 8401 cells. GBM 8401 cells were incubated with different concentrations of PEITC and $500 \mu \mathrm{M}$ TMZ for $48 \mathrm{~h}$ to determine the effects of PEITC on cell migration. The scratch wound healing assay was performed, and the results are shown in Fig. 2. An apparent and gradual increase in cells in the wounded zone at different concentrations of PEITC was observed with light microscopy. The migration inhibition rates were $12.7,42.4,44.3$ and $44.2 \%$ after cells were treated with 0,2 and $4 \mu \mathrm{M}$ PEITC and $500 \mu \mathrm{M}$ TMZ for $48 \mathrm{~h}$, respectively (Fig. 2B). The effects of PEITC on the migration of GBM 8401 cells as determined from the scratch wound healing assay were dose-dependent. 


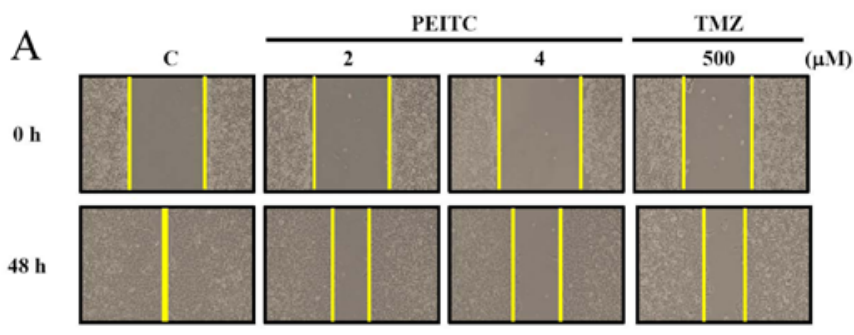

B

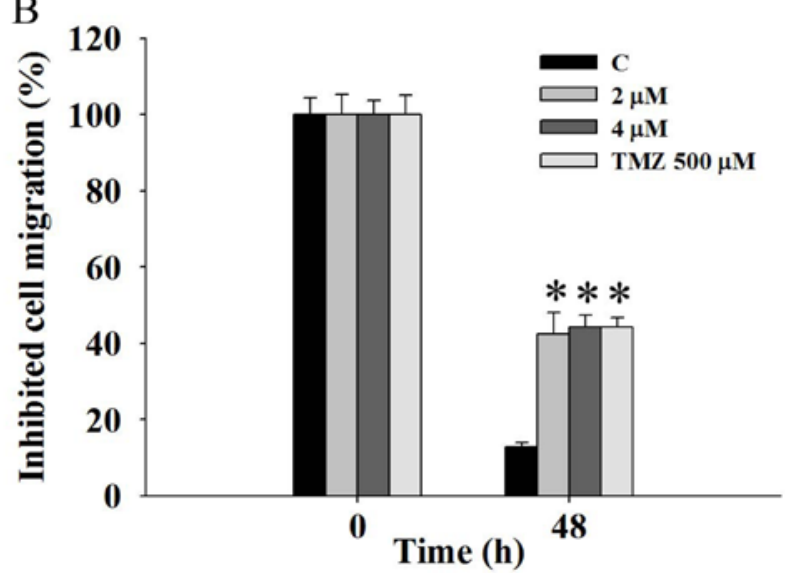

Figure 2. Effects of PEITC on the migration of GBM 8401 cells in a scratch wound healing migration assay. GBM 8401 cells were placed on a plate and a wound line was made with a pipette tip. The cells were incubated with 0,2 and $4 \mu \mathrm{M}$ PEITC or $500 \mu \mathrm{M}$ TMZ for 0 and $48 \mathrm{~h}$. (A) Cell migration was assessed by microscopy at the indicated time-points at x100 magnification. (B) Migration inhibition rates were determined at X100 magnification. ${ }^{*} \mathrm{P}<0.05$, significant difference between PEITC-treated or TMZ-treated groups and the control.

Results from the Transwell migration assay indicated that PEITC significantly inhibited the migration of GBM 8401 cells at concentrations between 2 and $4 \mu \mathrm{M}$ (Fig. 3), and the percentage of inhibition ranged from 46.89 to $15.75 \%$ when cells were incubated with PEITC for $48 \mathrm{~h}$ (Fig. 3B). These effects of PEITC on the migration of GBM 8401 cells as determined by the Transwell migration assay were also dosedependent. TMZ also had an inhibitory effect on GBM 8401 cell migration at the concentration of $500 \mu \mathrm{M}$.

PEITC inhibits the invasion of GBM 8401 cells. GBM 8401 cells were able to invade through a filter coated with Matrigel from the upper to the lower chamber in the control (Fig. 4), while penetration of the filter by GBM 8401 cells was inhibited by PEITC at concentrations between 2 and $4 \mu \mathrm{M}$. The percentage of inhibition ranged from 27.80 to $7.31 \%$ after a 48-h treatment (Fig. 4B). The effects of PEITC on invasion were in a dose-dependent manner. The invasion of GBM 8401 cells was also inhibited by $500 \mu \mathrm{M}$ TMZ.

PEITC decreases the enzyme activity of MMP-2 in GBM 8401 cells. Gelatin zymography assay indicated that the enzyme activity of MMP-2 was reduced in a dose-dependent manner after GBM 8401 cells were treated with 2 and $4 \mu \mathrm{M}$ PEITC for 24 and $48 \mathrm{~h}$ (Fig. 5). The enzyme activity of MMP-2 were also decreased after cells were treated with $500 \mu \mathrm{M}$ TMZ for 24 and 48 h (Fig. 5).

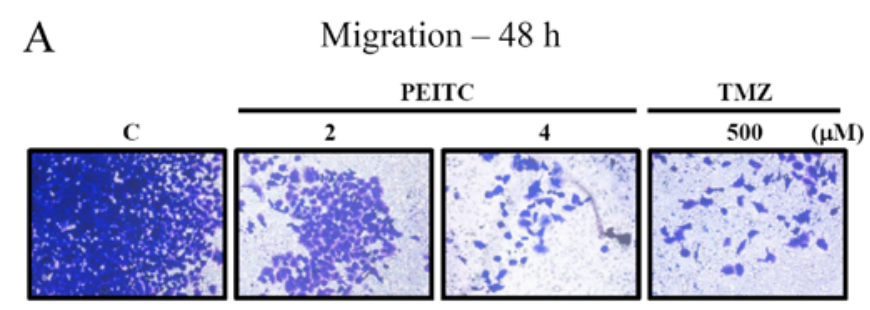

B

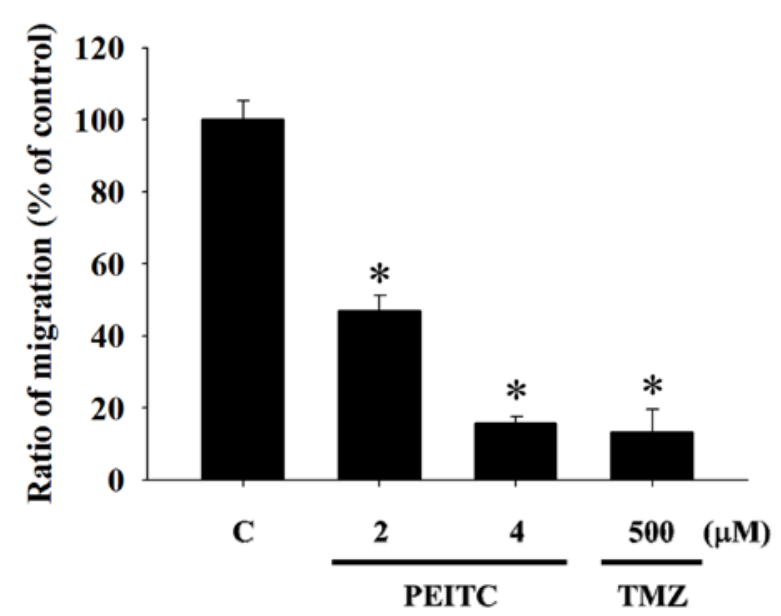

Figure 3. PEITC inhibits the migration of GBM 8401 cells. GBM 8401 cells $\left(3.2 \times 10^{4}\right.$ cells/filter) were treated with 0,2 and $4 \mu \mathrm{M}$ PEITC or $500 \mu \mathrm{M} \mathrm{TMZ}$ for $48 \mathrm{~h}$. (A) Cells on the Transwell filter that migrated to the lower surface of the filter were stained with crystal violet, and were photographed under a light microscope at x200 magnification. (B) Cells from the lower chamber were counted at $\mathrm{x} 200$ magnification. ${ }^{*} \mathrm{P}<0.05$, significant difference between PEITC-treated or TMZ-treated groups and the control.

PEITC inhibits the levels of proteins associated with migration and invasion in GBM 8401 cells. Western blot assay was applied to determine the effects of PEITC and TMZ on the levels of proteins associated with the migration and invasion of GBM 8401 cells. PEITC decreased the protein levels of Ras, uPA, RhoA, GRB2 (Fig. 6A), p-p38, p-JNK, p-ERK, p65 (Fig. 6B), SOS1, MMP-2, MM-9 and MMP-13 (Fig. 6C) in a dose-dependent manner after cells were treated with 2 and $4 \mu \mathrm{M}$ PEITC for $48 \mathrm{~h}$. TMZ reduced the protein levels of Ras, uPA, RhoA, GRB2, p-p38, p-JNK, p-ERK, p65, SOS1, MMP-2, MMP-9 and MMP-13 (Fig. 6).

PEITC inhibits mRNA expression levels in GBM 8401 cells. To investigate the effects of PEITC on the expression of migration- and invasion-associated genes in GBM 8401 cells, the cells were treated with 2 and $4 \mu \mathrm{M}$ PEITC for 24 and $48 \mathrm{~h}$. Real-time PCR analyses were applied to assess the mRNA expression levels of these genes. PEITC inhibited the mRNA levels of MMP-2 (Fig. 7A), MMP-7 (Fig. 7B), MMP-9 (Fig. 7C) and RhoA (Fig. 7D) in a dose- and time-dependent manner.

\section{Discussion}

Several studies have investigated the effects of PEITC on human glioma cells $(23,24)$. In our previous study, PEITC was found to induce the apoptosis of human brain glioblastoma 
A
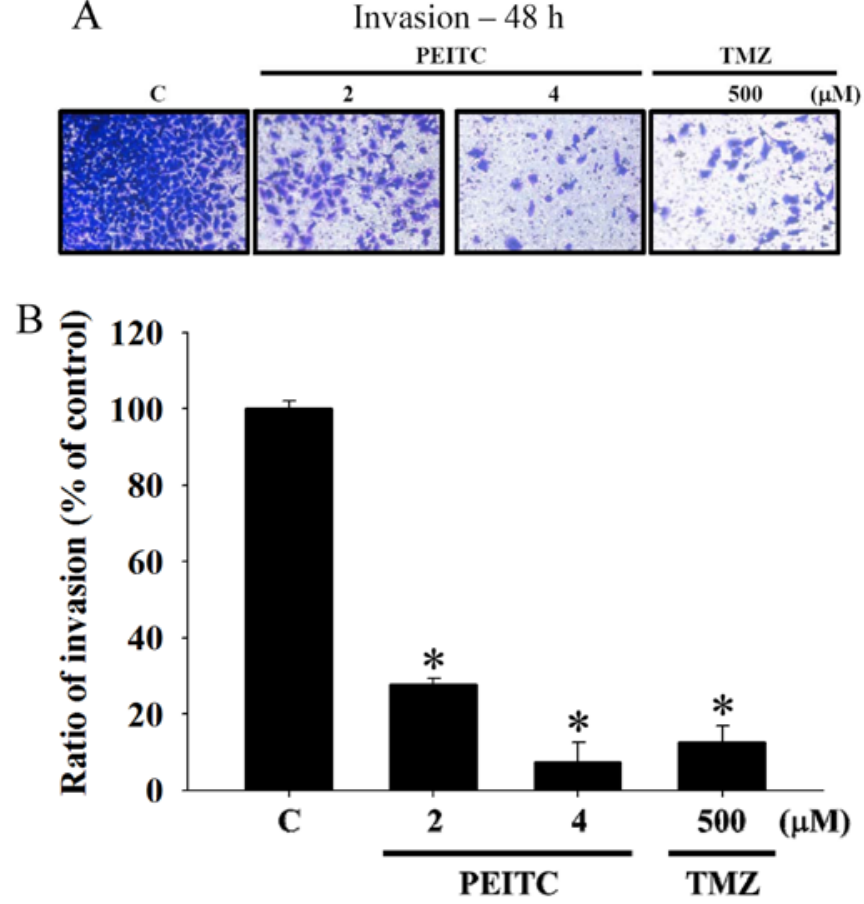

Figure 4. PEITC inhibits the migration of GBM 8401 cells. GBM 8401 cells $\left(3.2 \times 10^{4}\right.$ cells/filter) were treated with 0,2 and $4 \mu \mathrm{M}$ PEITC or $500 \mu \mathrm{M} \mathrm{TMZ}$ for 48 h. (A) Cells on the Transwell filter that penetrated through the Matrigel to the lower surface of the filter were stained with crystal violet, and were photographed under a light microscope at x200 magnification. (B) Cells from the lower chamber were counted at $\times 200$ magnification. ${ }^{*} \mathrm{P}<0.05$, significant difference between PEITC-treated or TMZ-treated groups and the control.

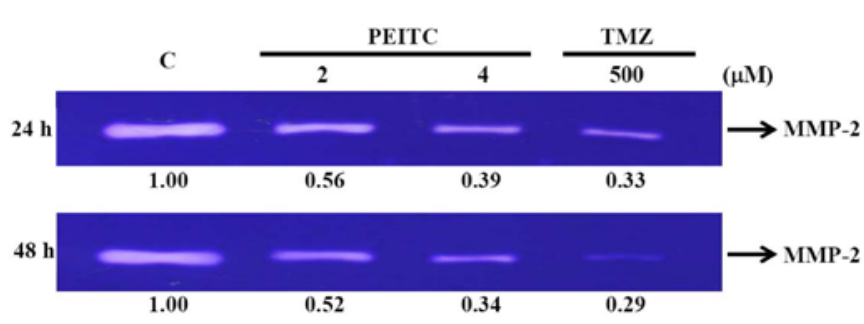

Figure 5. Effects of PEITC on the enzyme activitiy of MMP-2 in GBM 8401 cells. Cells were treated with 0,2 and $4 \mu \mathrm{M}$ PEITC or $500 \mu \mathrm{M}$ TMZ for 24 and $48 \mathrm{~h}$. Cells were harvested for examination of MMP-2 activity following each treatment and MMP-2 activity was determined by gelatin zymography assay as described in Materials and methods.

cells (13). In the present study, the cell morphology of GBM 8401 cells was not significantly altered (Fig. 1A), and the cell viability was not significantly decreased following exposure to PEITC at a concentration as high as $4 \mu \mathrm{M}$, or $500 \mu \mathrm{M}$ TMZ after a $24-$ and 48 -h treatment (Fig. 1B). Thus, the concentrations of PEITC and TMZ for cell migration and invasion studies were determined. Based on the Transwell migration assay, PEITC significantly inhibited the migration of GBM 8401 cells at concentrations between 2 and $4 \mu \mathrm{M}$ in a dosedependent manner (Fig. 3), and the percentage of inhibition ranged from 46.89 to $15.75 \%$ when cells were incubated with PEITC for $48 \mathrm{~h}$ (Fig. 3B). Based on the invasion assay, PEITC also significantly inhibited the invasion of GBM 8401 cells at concentrations between 2 and $4 \mu \mathrm{M}$ in a dose-dependent manner (Fig. 4), and the percentage of inhibition ranged from
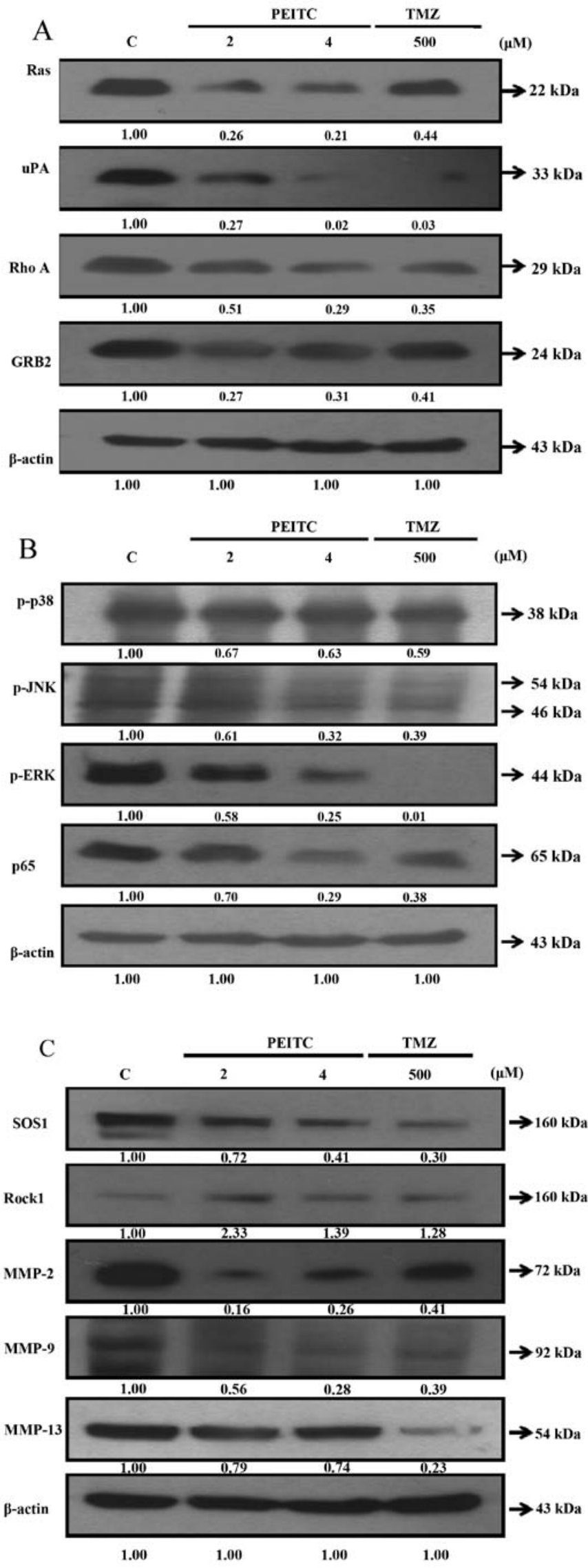

Figure 6. Effects of PEITC on the levels of proteins associated with migration and invasion in GBM 8401 cells. Cells were treated with 0,2 and $4 \mu \mathrm{M}$ PEITC or $500 \mu \mathrm{M} \mathrm{TMZ}$ for $48 \mathrm{~h}$. The proteins levels from each sample were determined by SDS-PAGE and western blotting. (A) Ras, uPA, Rho A, GRB2; (B) p-p38, p-JNK, p-ERK, p65 and (C) SOS1, Rock1, MMP-2, MMP-9 and MMP-13. 

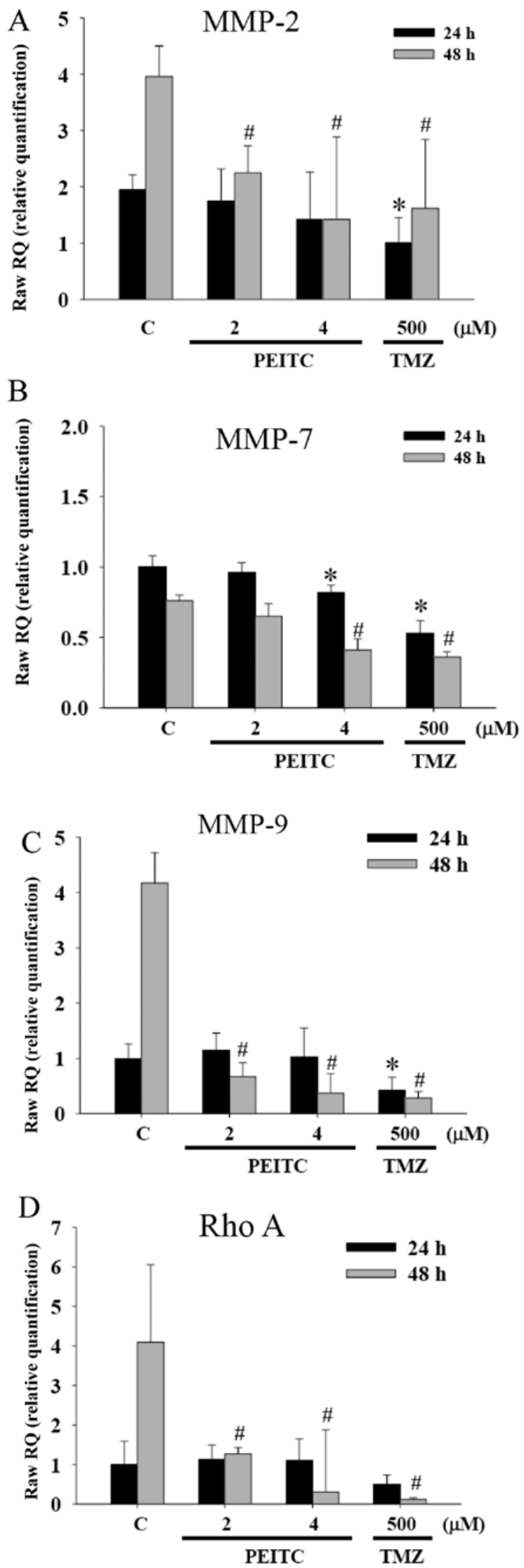

Figure 7. PEITC inhibits mRNA expression levels in GBM 8401 cells. Cells were treated with 0,2 and $4 \mu \mathrm{M}$ PEITC or $500 \mu \mathrm{M} \mathrm{TMZ}$ for 24 and $48 \mathrm{~h}$. RNA samples were reverse-transcribed to obtain cDNA for real-time PCR. The ratios of gene expression to that for GAPDH are presented for (A) MMP-2, (B) MMP-7, (C) MMP-9 and (D) RhoA. Data represent the mean \pm SD of three experiments. Significantly different between PEITC treatment and control groups $\left(\right.$ $\left.\mathrm{P}<0.05,{ }^{\text {"}} \mathrm{P}<0.05\right)$.

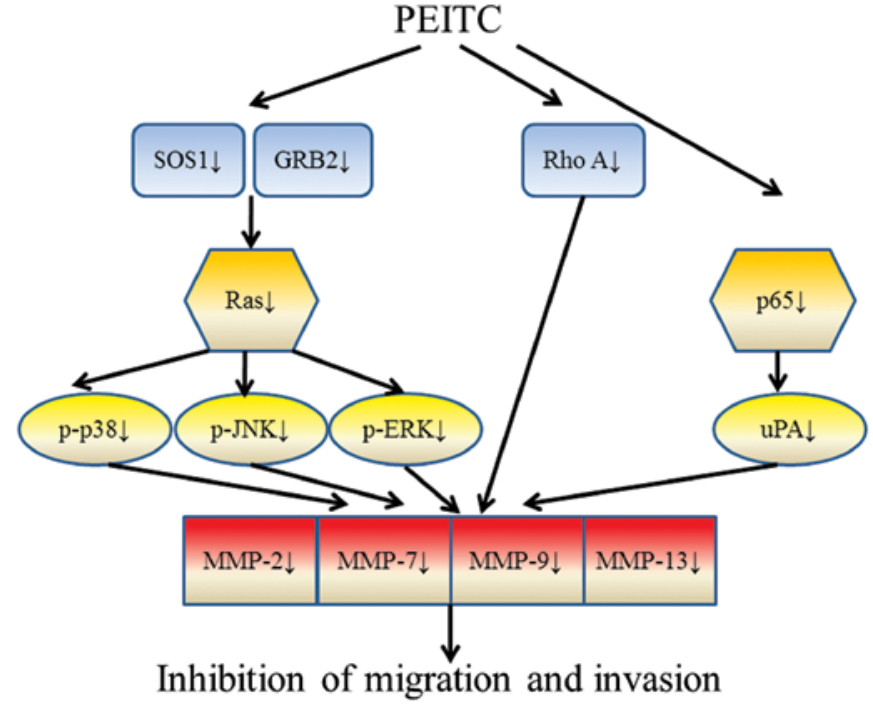

Figure 8 . The possible signaling pathways involved in the inhibition of migration and invasion in human glioblastoma multiforme GBM 8401 cells by PEITC.

27.80 to $7.31 \%$ after a 48 -h treatment (Fig. 4B). The current standard chemotherapy, TMZ, also had inhibitory effects on the migration and invasion of GBM 8401 cells at the concentration of $500 \mu \mathrm{M}$.

MMPs, a family of zinc-dependent endopeptidases, play roles in brain development, synaptic plasticity and repair after injury to the pathogenesis of various brain disorders (25). MMP-mediated extracellular matrix (ECM) degradation promotes tumor invasion, progression and is involved in angiogenesis and metastasis. MMPs are able to degrade almost all known ECM components and play important roles in mediating glioblastoma tumor cell invasion (26). The levels of MMP-2, MMP-9 and membrane type 1 (MT1)-MMP expression in gliomas are higher than those in normal brain tissue. MMP-13 enzymatic activity was found to be critical to the highly invasive potential of cancer stem cells of human glioblastoma cell line U251 (27). The levels of MMP-7 expression are correlated with tumor aggressiveness and poor prognosis in solid tumors, but they are highly variable in patients with glioblastoma (27). Cross-talk between the tumor and the surrounding stroma to regulate MMP-7 exists; the expression of MMP-7 in human U87 glioma cells is low in culture, but higher when the cells are implanted within the brain. In the present study, PEITC reduced the enzyme activity of MMP-2 in a dose- and timedependent manner after GBM 8401 cells were treated with 2 and $4 \mu \mathrm{M}$ PEITC for 24 and $48 \mathrm{~h}$ (Fig. 5). PEITC also decreased the protein levels of MMP-2, MMP-9 and MMP-13 (Fig. 6C) in a dose-dependent manner after cells were treated with 2 and $4 \mu \mathrm{M}$ PEITC for $48 \mathrm{~h}$. PEITC inhibited the mRNA levels of MMP-2 (Fig. 7A), MMP-7 (Fig. 7B), MMP-9 (Fig. 7C) in a dose- and time-dependent manner. Taken together, PEITC may inhibit the migration and invasion of GBM 8401 cells through reduction in the enzyme activity of MMP-2, the protein levels of MMP-2, MMP-9 and MMP-13, and the mRNA levels of MMP-2, MMP-7 and MMP-9.

uPA converts plasminogen to plasmin-activating MMPs, and GBM cell invasion may be enhanced by uPA-mediated 
direct activation of MMP-9 (28). The enhanced invasive capacity of peritumoral cells in GBM requires simultaneous Rac and RhoA activation (29). Knockdown of GRB2, mediating receptor tyrosine kinase-induced activation of RAS and downstream signaling, can reduce invasive activity of breast cancer (30). Epidermal growth factor receptor (EGFR) vIII-mediated migration and transformation of U87MG (PTEN-mutant) glioblastoma cells was found to be downregulated by the effects of signal regulatory protein $\alpha 1$ (SIRP $\alpha 1)$ on the activation loop of SHP-2/FAK/GRB2/SOS-1/MAPK (31). Knockdown of RhoA inhibited the expression of p-JNK and phospho-c-Jun (p-c-Jun), reduced MMP-2 activity and cell invasion in human glioma U251 cells under hypoxic conditions (32). The ROCK-dependent signaling pathway is involved in glioma migration, and antidromic effects on glioma migration are executed by selective knockdown of either ROCK1 or ROCK2 (33). ROCK1 knockdown inhibits cell proliferation, while ROCK 2 knockdown promotes it. In the present study, PEITC inhibited the protein levels of Ras, uPA, RhoA, GRB2 (Fig. 6A), p-p38, p-JNK, p-ERK, p65 (Fig. 6B) and SOS1 (Fig. 6C) in a dose-dependent manner after cells were treated with 2 and $4 \mu \mathrm{M}$ PEITC for $48 \mathrm{~h}$. PEITC decreased the mRNA levels of RhoA (Fig. 7D) in a dose- and time-dependent manner. Taken together, PEITC may inhibit the migration and invasion of GBM 8401 cells through reduction in the protein levels of Ras, uPA, RhoA, GRB2, p-p38, p-JNK, p-ERK, p65, SOS1, Rock1 and the mRNA levels of RhoA.

In conclusion, our experiments indicated that PEITC has potent anticancer activities through the inhibition of the migration and invasion of GBM 8401 cells. PEITC decreased the expression levels of MMP-2, MMP-7, MMP-9, MMP-13, Ras, uPA, RhoA, GRB2, p-p38, p-JNK, p-ERK, p65 and SOS1 in GBM 8401 cells in vitro (Fig. 8). PEITC may have therapeutic potential, and our findings have elucidated the possible molecular mechanisms and signaling pathways of the anticancer properties of PEITC in regards to human brain glioblastoma cells.

\section{Acknowledgements}

The present study was supported by grant TCVGH-1044903B from the Taichung Veterans General Hospital, Taichung, Taiwan.

\section{References}

1. Stupp R, Mason WP, van den Bent MJ, et al; European Organisation for Research and Treatment of Cancer Brain Tumor and Radiotherapy Groups; National Cancer Institute of Canada Clinical Trials Group: Radiotherapy plus concomitant and adjuvant temozolomide for glioblastoma. N Engl J Med 352: 987-996, 2005

2. Lun M, Lok E, Gautam S, Wu E and Wong ET: The natural history of extracranial metastasis from glioblastoma multiforme. J Neurooncol 105: 261-273, 2011.

3. Yang LJ, Zhou CF and Lin ZX: Temozolomide and radiotherapy for newly diagnosed glioblastoma multiforme: A systematic review. Cancer Invest 32: 31-36, 2014.

4. Chaichana KL, Jusue-Torres I, Navarro-Ramirez R, Raza SM, Pascual-Gallego M, Ibrahim A, Hernandez-Hermann M, Gomez L, Ye X, Weingart JD, et al: Establishing percent resection and residual volume thresholds affecting survival and recurrence for patients with newly diagnosed intracranial glioblastoma. Neuro-oncol 16: 113-122, 2014.
5. Moon YJ, Brazeau DA and Morris ME: Dietary phenethyl isothiocyanate alters gene expression in human breast cancer cells. Evid Based Complement Alternat Med 2011: 462525, 2011. http://dx.doi.org/10.1155/2011/462525.

6. Antosiewicz J, Ziolkowski W, Kar S, Powolny AA and Singh SV: Role of reactive oxygen intermediates in cellular responses to dietary cancer chemopreventive agents. Planta Med 74: 1570-1579, 2008.

7. Chen YR, Han J, Kori R, Kong AN and Tan TH: Phenylethyl isothiocyanate induces apoptotic signaling via suppressing phosphatase activity against c-Jun N-terminal kinase. J Biol Chem 277: 39334-39342, 2002.

8. Hu R, Kim BR, Chen C, Hebbar V and Kong AN: The roles of JNK and apoptotic signaling pathways in PEITC-mediated responses in human HT-29 colon adenocarcinoma cells. Carcinogenesis 24: 1361-1367, 2003.

9. Jakubikova J, Bao Y and Sedlak J: Isothiocyanates induce cell cycle arrest, apoptosis and mitochondrial potential depolarization in HL-60 and multidrug-resistant cell lines. Anticancer Res 25: 3375-3386, 2005.

10. Kang L and Wang ZY: Breast cancer cell growth inhibition by phenethyl isothiocyanate is associated with down-regulation of oestrogen receptor-alpha36. J Cell Mol Med 14: 1485-1493, 2010.

11. Telang U, Brazeau DA and Morris ME: Comparison of the effects of phenethyl isothiocyanate and sulforaphane on gene expression in breast cancer and normal mammary epithelial cells. Exp Biol Med (Maywood) 234: 287-295, 2009.

12. Tseng E, Scott-Ramsay EA and Morris ME: Dietary organic isothiocyanates are cytotoxic in human breast cancer MCF-7 and mammary epithelial MCF-12A cell lines. Exp Biol Med (Maywood) 229: 835-842, 2004.

13. Chou YC, Chang MY, Wang MJ, Harnod T, Hung CH, Lee HT, Shen CC and Chung JG: PEITC induces apoptosis of human brain glioblastoma GBM8401 cells through the extrinsic- and intrinsic -signaling pathways. Neurochem Int 81: 32-40, 2015.

14. Gupta P, Adkins C, Lockman P and Srivastava SK: Metastasis of breast tumor cells to brain is suppressed by phenethyl isothiocyanate in a novel in vivo metastasis model. PLoS One 8: e67278, 2013.

15. Lai KC, Hsu SC, Kuo CL, Ip SW, Yang JS, Hsu YM, Huang HY, Wu SH and Chung JG: Phenethyl isothiocyanate inhibited tumor migration and invasion via suppressing multiple signal transduction pathways in human colon cancer HT29 cells. J Agric Food Chem 58: 11148-11155, 2010.

16. Lin CC, Chen JT, Yang JS, Lu HF, Hsu SC, Tan TW, Lin YT, Ma YS, Ip SW, Wu JJ, et al: Danthron inhibits the migration and invasion of human brain glioblastoma multiforme cells through the inhibition of mRNA expression of focal adhesion kinase, Rho kinases-1 and metalloproteinase-9. Oncol Rep 22: 1033-1037, 2009.

17. Lu HF, Lai TY, Hsia TC, Tang YJ, Yang JS, Chiang JH, Lu CC, Liu CM, Wang HL and Chung JG: Danthron induces DNA damage and inhibits DNA repair gene expressions in GBM 8401 human brain glioblastoma multiforms cells. Neurochem Res 35: 1105-1110, 2010.

18. Shang HS, Chang JB, Lin JH, Lin JP, Hsu SC, Liu CM, Liu JY, Wu PP, Lu HF, Au MK, et al: Deguelin inhibits the migration and invasion of U-2 OS human osteosarcoma cells via the inhibition of matrix metalloproteinase-2/-9 in vitro. Molecules 19: 16588-16608, 2014.

19. Lu KW, Chen JC, Lai TY, Yang JS, Weng SW, Ma YS, Lu PJ, Weng JR, Chueh FS, Wood WG, et al: Gypenosides inhibits migration and invasion of human oral cancer SAS cells through the inhibition of matrix metalloproteinase-2 -9 and urokinaseplasminogen by ERK1/2 and NF-kappa B signaling pathways. Hum Exp Toxicol 30: 406-415, 2011.

20. Liao CL, Lai KC, Huang AC, Yang JS, Lin JJ, Wu SH, Gibson Wood W, Lin JG and Chung JG: Gallic acid inhibits migration and invasion in human osteosarcoma U-2 OS cells through suppressing the matrix metalloproteinase-2/-9, protein kinase $\mathrm{B}$ (PKB) and PKC signaling pathways. Food Chem Toxicol 50: 1734-1740, 2012.

21. Ho CC, Huang AC, Yu CS, Lien JC, Wu SH, Huang YP, Huang HY, Kuo JH, Liao WY, Yang JS, et al: Ellagic acid induces apoptosis in TSGH8301 human bladder cancer cells through the endoplasmic reticulum stress- and mitochondriadependent signaling pathways. Environ Toxicol 29: 1262-1274, 2014. 
22. Lin HJ, Su CC, Lu HF, Yang JS, Hsu SC, Ip SW, Wu JJ, Li YC, Ho CC, Wu CC, et al: Curcumin blocks migration and invasion of mouse-rat hybrid retina ganglion cells (N18) through the inhibition of MMP-2, -9, FAK, RhoA and Rock-1 gene expression. Oncol Rep 23: 665-670, 2010.

23. Gupta B, Chiang L, Chae K and Lee DH: Phenethyl isothiocyanate inhibits hypoxia-induced accumulation of HIF-1 $\alpha$ and VEGF expression in human glioma cells. Food Chem 141: 1841-1846, 2013

24. Lee DH, Kim DW, Lee HC, Lee JH and Lee TH: Phenethyl isothiocyanate sensitizes glioma cells to TRAIL-induced apoptosis. Biochem Biophys Res Commun 446: 815-821, 2014.

25. Kim YS and Joh TH: Matrix metalloproteinases, new insight into the understanding of neurodegenerative disorders. Biomol Ther (Seoul) 20: 133-143, 2012.

26. Chintala SK, Tonn JC and Rao JS: Matrix metalloproteinases and their biological function in human gliomas. Int J Dev Neurosci 17: 495-502, 1999

27. Inoue A, Takahashi H, Harada H, Kohno S, Ohue S, Kobayashi K, Yano H, Tanaka J and Ohnishi T: Cancer stem-like cells of glioblastoma characteristically express MMP-13 and display highly invasive activity. Int J Oncol 37: 1121-1131, 2010.

28. Zhao Y, Lyons CE Jr, Xiao A, Templeton DJ, Sang QA, Brew K and Hussaini IM: Urokinase directly activates matrix metalloproteinases-9: A potential role in glioblastoma invasion. Biochem Biophys Res Commun 369: 1215-1220, 2008.
29. Ruiz-Ontañon P, Orgaz JL, Aldaz B, Elosegui-Artola A, Martino J, Berciano MT, Montero JA, Grande L, Nogueira L, Diaz-Moralli S, et al: Cellular plasticity confers migratory and invasive advantages to a population of glioblastoma-initiating cells that infiltrate peritumoral tissue. Stem Cells 31: 1075-1085, 2013.

30. Xu Y, Zhang H, Lit LC, Grothey A, Athanasiadou M, Kiritsi M, Lombardo Y, Frampton AE, Green AR, Ellis IO, et al: The kinase LMTK3 promotes invasion in breast cancer through GRB2mediated induction of integrin $\beta 1$. Sci Signal 7: ra58, 2014.

31. Kapoor GS and O'Rourke DM: SIRPalpha1 receptors interfere with the EGFRvIII signalosome to inhibit glioblastoma cell transformation and migration. Oncogene 29: 4130-4144, 2010.

32. Tong JJ, Yan Z, Jian R, Tao H, Hui OT and Jian C: RhoA regulates invasion of glioma cells via the c-Jun NH2-terminal kinase pathway under hypoxia. Oncol Lett 4: 495-500, 2012.

33. Mertsch S and Thanos S: Opposing signaling of ROCK1 and ROCK 2 determines the switching of substrate specificity and the mode of migration of glioblastoma cells. Mol Neurobiol 49: 900-915, 2014. 